
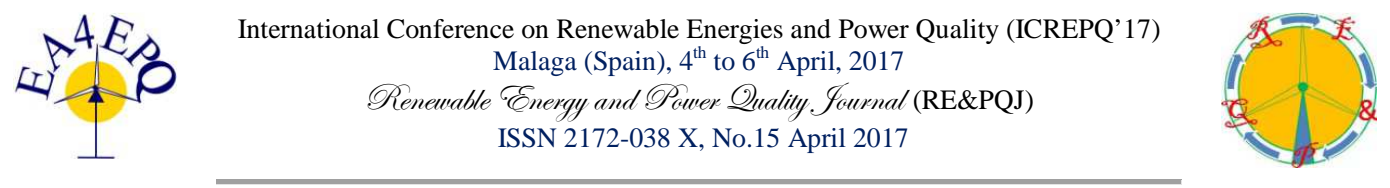

\title{
Corrosion testing of a diesel engine common rail system using various types of biodiesel
}

\author{
A. Alcántara-Carmona ${ }^{1}$, J. Sáez-Bastante ${ }^{1}$ and M.P. Dorado ${ }^{1}$ \\ ${ }^{1}$ Department of Physical Chemistry and Applied Thermodynamics \\ E.P.S., University of Córdoba \\ Campus Universitario de Rabanales - 14071 Córdoba (Spain) \\ Phone/Fax number: +0034 957 218332/8417, e-mail: aalcantara@uco.es, q92sabaj@uco.es, pilar.dorado@uco.es
}

\begin{abstract}
In this paper, the behavior of different types of biodiesel (from rapeseed, soybean, coconut and palm oils) in contact with different parts of a common rail injection system was evaluated. Stability tests were carried out by static immersion of test pieces in biodiesel at two different temperatures, $50^{\circ} \mathrm{C}$ and $75^{\circ} \mathrm{C}$. After 15 days of immersion, interaction between pieces and biodiesel was evaluated considering two parameters: mass variation of pieces and biodiesel acid value (AV). A mass loss in both injector and pipes was found, no matter which biodiesel was used. In case soybean oil biodiesel was used, a slightly lower loss was achieved. On the other hand, coconut oil biodiesel showed a significant acid value increase with respect to the others. The temperature increase influenced mass loss and acid value increase.
\end{abstract}

\section{Key words}

Biofuel, materials compatibility, acid value variation, mass loss, oxidation.

\section{Introduction}

Biodiesel is mainly a biofuel derived from vegetable oils and animal fats that is synthesized by a transesterification with a short-chain alcohol, generally methanol or ethanol, to yield fatty acid alkyl esters (biodiesel) and glycerol, as a by-product [1]. Among others, its main features are its renewability, its high flash point and its ability to be mixed with diesel fuel. However, diesel fuel and biodiesel have a very different chemical composition. In this sense, diesel fuel is composed of saturated hydrocarbons (primarily paraffins and isoparaffins, including cycloparaffins) and aromatic hydrocarbons compounds (including naphthalenes and alkylbenzene). This disparity in terms of chemical composition presumes differences in fuel stability and engine oxidation. Double bonds present in fatty acids that make up fatty acid alkyl esters are reaction points where atmospheric oxygen may influence biofuel quality.

In this sense, biodiesel oxidation has been studied by different authors. Tsuchiya et al. ensure that biodiesel oxidation process increase with free water content. Moreover, esters may become different carboxylic monoacids such as acetic acid and propionic acid, among others, which are responsible of corrosion. The above acids can generate pitting process on the metal surface. However, most of them could be reduced with the help of antioxidants [2].

Another study carried out by Labeckas and Slavinskas showed that rapeseed oil biodiesel presents a free water content value about 2.7 times higher than others. This fact can lead to an increase in both density and viscosity values, stimulating acidity, as well as reducing cetane 
number, thus increasing corrosion [3].

On the other hand, Fazal et al. studied the corrosion of aluminum (99\% commercially pure), copper and stainless steel in contact with palm oil and palm oil biodiesel. After an exposure time of $1200 \mathrm{~h}$, it was found that the corrosion rate of copper and aluminum in contact with biodiesel was greater than that presented by diesel fuel, while the stainless steel did not show significant changes. The corrosion rates of copper, aluminum and stainless steel were approximately $0.586,0.202$ and 0.015 $\mathrm{mm} /$ year, respectively [4].

Singh and Singh found that biodiesel is much more corrosive than diesel fuel when used in metals and elastomers, while stainless steel do not show pitting corrosion [5]. Also, other authors report that unsaturated double bonds make biodiesel more susceptible to oxidation.

Along the different parts of the engine feeding system, biodiesel comes into contact with metallic and nonmetallic materials. They are ferrous metal materials, such as casting and steel, and non-ferrous metals, such as aluminum alloys. The aforementioned authors have studied commercially pure metals, but there are few studies on actual pieces or in use. These pieces are mostly metal alloys, also affected by forming processes, thermal treatments, surface treatments and other typical manufacturing techniques which may further affect their reactivity with biodiesel. Studies considering the use of biodiesel in diesel engines only consider corrosion of $\mathrm{Cu}$, but degradation of biodiesel and corrosion or alteration of materials goes beyond. This raises the undeniable need to further study the compatibility of different biodiesel types with different engine materials [6].

\section{Materials and methods}

\subsection{Materials}

\subsubsection{Vegetable oils}

Soybean oil was purchased from Guinama (Alboraya, Valencia, Spain), coconut oil from Acofarma (Terrassa, Barcelona, Spain), palm oil from Químics Dalmau (Barcelona, Spain) and rapeseed oil was provided by IFAPA (Instituto de Formación Agraria y Pesquera, Córdoba, Spain).

\subsubsection{Reagents}

Potassium hydroxide and methanol for biodiesel production were acquired from Panreac Química (Barcelona, España). To determine acid and peroxide values, PA absolute ethanol, diethyl ether stabilized with 6 ppm of BTH PA-ACS, phenolphthalein solution (10 $\mathrm{g} / \mathrm{L})$, methanol PA-ACS-ISO and potassium hydroxide (85\% purity), acetic acid, PA-ACS water, soluble starch, potassium iodide, $0.1 \mathrm{~N}$ sodium thiosulfate and trichloromethane stabilized with ethanol were used, all supplied by Panreac Química. To determine water content, an anodic solution containing sulfur dioxide, imidazole and potassium iodide, using methanol as solvent and a cathodic solution were used. Reagents were purchased from Sigma-Aldrich (Steinheim, Germany). Finally, hexane and sodium methylate, from Panreac, were used for fatty acid determination.

\subsubsection{Chromatographic analysis}

A Perkin gas chromatograph instrument provided with a flame ionization detector (GC-FID) model Clarus 500 was used. The equipment was purchased from PerkinElmer (Shelton, Connecticut, USA) provided of a SGE BPX70 capillary column (30 m length, $0.32 \mathrm{~mm}$ inner diameter and $0.25 \mu \mathrm{m}$ film).

\subsubsection{Injector and pipes}

Corrosion tests were carried out using a Bosch common rail injector, manufactured in Korea with model number 0445110269 for Chevrolet vehicles and its associated pipe. Figure 1 shows both injector and pipe. 


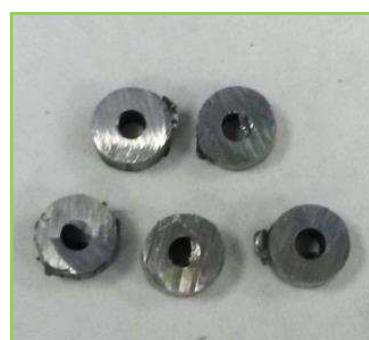

a

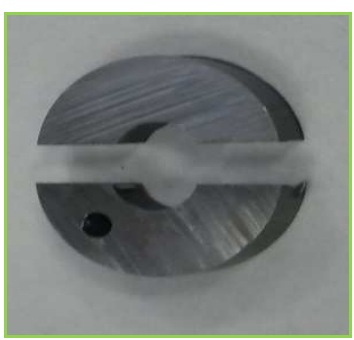

b
Fig. 1. (a) Pipe pieces and (b) injector pieces

\subsection{Methods}

\subsubsection{Biodiesel production}

Biodiesel production for each type of oil were conducted based on previous optimization studies in batch process [7], as shown in Table I.

Table I - Biodiesel synthesis optimal conditions

\begin{tabular}{|c|c|c|c|c|}
\hline Oil & $\begin{array}{c}\text { Catalyst } \\
(\% \text { wt. })\end{array}$ & $\begin{array}{c}\text { Methanol } \\
\text { to oil } \\
\text { molar } \\
\text { ratio }\end{array}$ & $\begin{array}{c}\text { Temperature } \\
\left({ }^{\circ} \mathrm{C}\right)\end{array}$ & $\begin{array}{c}\text { Reaction } \\
\text { time } \\
(\mathrm{min})\end{array}$ \\
\hline Rapeseed & 1.7 & $6.6: 1$ & 60 & 60 \\
\hline Soybean & 1.8 & $6.2: 1$ & 65 & 40 \\
\hline Coconut & 1.5 & $6: 1$ & 60 & 50 \\
\hline Palm & 1.5 & $6: 1$ & 60 & 50 \\
\hline
\end{tabular}

2.2.2 Vegetable oil and biodiesel characterization

Physical tests consisting of density and kinematic viscosity were performed according to EN ISO 3675 and EN ISO 3104, respectively. Acid value was determined according to ISO 660, while peroxide value was determined by EN ISO 3960. Water content was determined according to EN ISO 12937, using a Karl Fischer Coulumeter DL32 (Schawerzenbach, Switzerland). Flash point was measured using a Seta Flash series 3 plus following the standard EN ISO 2719, from Instrumentación Analítica (Madrid, Spain). High calorific was measured by an Optika SRL calorimeter pump, model IKA C200 (Ponteranica, Italy). The analyses were carried out following ASTM D240 standard.

\subsubsection{Fatty acid determination}

Fatty acid content was determined by GC-FID, following
EN 14103 standard.

\subsubsection{Preparation of metal samples}

Pieces were cut using a metallographic cutting machine, cooled with water and showing a slow advance to avoid changes in metallic surfaces. Samples were washed with water and surfaces were polished mechanically with a polisher, using abrasive papers of silicon carbide (400 and $1200 \mu \mathrm{m}$ ) to provide a fine surface finish. Samples were quickly washed with distilled water and acetone. Finally, they were dried with compressed air and introduced into glass bottles containing biodiesel (Figure 2).

\subsubsection{Static immersion tests}

These tests consisted in placing pieces of both injector and pipe in glass bottles containing biodiesel, into a thermostated water bath, at $50^{\circ} \mathrm{C}$ and $75^{\circ} \mathrm{C}, 360 \mathrm{~h}(15$ days). Previously, pieces were weighed and the acid value of each type of biodiesel was determined (Figure 3). After the tests, each piece was weighed and biodiesel acid value was determined.

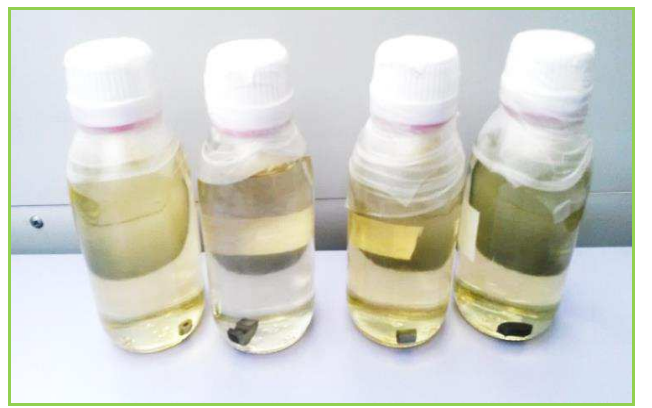

Fig. 2. Glass bottles containing both biodiesel and metal samples

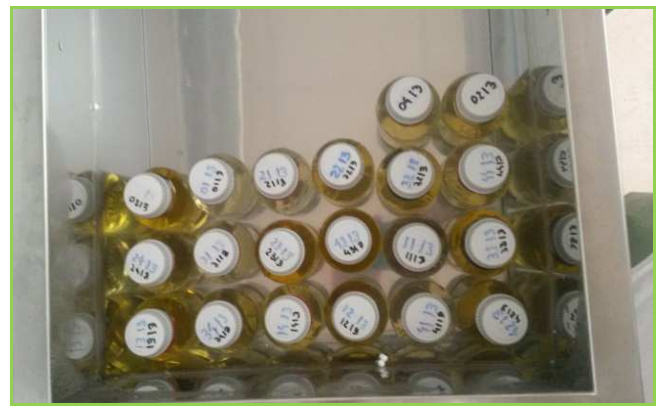

Fig. 3. Glass bottles in the thermostated water bath at $75^{\circ} \mathrm{C}$ during the test 


\section{Results and discussion}

Oil and biodiesel chemical composition, physical and chemical properties were determined. Results are shown in tables II y III.

Table II - Oil chemical composition

\begin{tabular}{|c|c|c|c|c|}
\hline PROPERTY & $\mathrm{RO}^{5}$ & $\mathrm{SO}^{6}$ & $\mathrm{CO}^{7}$ & $\mathrm{PO}^{8}$ \\
\hline \multicolumn{5}{|c|}{ FATTY ACID COMPOSITION (\%) } \\
\hline Caprylic (C8:0) & 0 & 0 & 9.5 & 0 \\
\hline Decanoic (C10:0) & 0 & 0 & 8 & 0 \\
\hline Lauric (C12:0) & 0 & 0 & 41 & 0.5 \\
\hline Miristic (C14:0) & 0 & 0.05 & 18 & 1.5 \\
\hline Palmitic (C16:0) & 3.87 & 11.05 & 9 & 45.5 \\
\hline Stearic (C18:0) & 2.12 & 3.87 & 3.8 & 4 \\
\hline Oleic (C18:1) & 66.73 & 25.85 & 7.5 & 38 \\
\hline Linoleic (C18:2) & 17.19 & 52.83 & 2.7 & 10 \\
\hline Linolenic (C18:3) & 10.09 & 6.55 & 0.5 & 0.5 \\
\hline Arachidic (C20:0) & 0 & 0.2 & 0 & 0 \\
\hline Behenic (C22:0) & 0 & 0.2 & 0 & 0 \\
\hline \multicolumn{5}{|c|}{ HYDROCARBON CHAIN PROPERTIES } \\
\hline LC (\%) 19.9 & 17.92 & 17.89 & 13.37 & 17 \\
\hline TUD (\%) ${ }^{2,10}$ & 131.38 & 151.16 & 14.4 & 59.5 \\
\hline PUD (\%) & 64.65 & 125.31 & 6.9 & 21.5 \\
\hline MUD (\%) & 66.73 & 25.85 & 7.5 & 38 \\
\hline
\end{tabular}

${ }^{1}$ Length of chain (LC); ${ }^{2}$ total unsaturation degree (TUD); polyunsaturation degree (PUD) and ${ }^{4}$ monounsaturation degree (MUD); ${ }^{5} \mathrm{RO}$ (rapeseed oil); ${ }^{6} \mathrm{SO}$ (soybean oil); ${ }^{7} \mathrm{CO}$ (coconut oil); ${ }^{8} \mathrm{PO}$ (palm oil) $;{ }^{9} \mathrm{LC}=\Sigma(n C n / 100)$, where $n$ is the number of carbon atoms of each fatty acid and $C n$ is the weight percentage of each methyl ester in the given fatty acid; ${ }^{10} \mathrm{TUD}=(1 \% \mathrm{MU}+2 \% \mathrm{DU}+3 \% \mathrm{TU}) /$, where $\% M U$ is the weight percentage of monounsaturated methyl esters, \%DU is the weight percentage of diunsaturated methyl esters and \% TU is the weight percentage of triunsaturated methyl esters.

European biodiesel standard EN 14214 limits for viscosity, density and acid value are $3.5-5 \mathrm{~mm}^{2} / \mathrm{s}, 860-$ $900 \mathrm{~kg} / \mathrm{m}^{3}$ and $0.5 \mathrm{mg} \mathrm{KOH} / \mathrm{g}$, respectively.

Table III - Biodiesel properties

\begin{tabular}{|c|c|c|c|c|}
\hline Property & $\mathrm{ROB}^{1}$ & $\mathrm{SOB}^{2}$ & $\mathrm{COB}^{3}$ & $\mathrm{POB}^{4}$ \\
\hline $\begin{array}{c}\text { Kinematic } \\
\text { viscosity, } \mu \\
(\mathrm{mm} / \mathrm{s}) \text { at } \\
40^{\circ} \mathrm{C}\end{array}$ & 4.2 & 3.9 & 4.8 & 4.7 \\
\hline $\begin{array}{c}\text { Density, } \rho \\
\left(\mathrm{kg} / \mathrm{m}^{3}\right) \\
\text { at } 15^{\circ} \mathrm{C}\end{array}$ & 884 & 884 & 897 & 890 \\
\hline $\begin{array}{c}\text { Acid value } \\
(\mathrm{mg} \mathrm{KOH} / \mathrm{g})\end{array}$ & 0.369 & 0.0663 & 0.0714 & 0.0663 \\
\hline
\end{tabular}

COB (coconut oil biodiesel) and ${ }^{4}$ POB (palm oil biodiesel)

\subsection{Mass variation}

Results show that after the test at $50^{\circ} \mathrm{C}$, each piece of injector reduced its mass $0.00004 \mathrm{~g}$ for rapeseed oil biodiesel, $0.00001 \mathrm{~g}$ for soybean oil biodiesel, $0.00002 \mathrm{~g}$ for coconut oil biodiesel and $0.00006 \mathrm{~g}$ for palm oil biodiesel. Likewise, at $75^{\circ} \mathrm{C}$, it was reduced $0.00015 \mathrm{~g}$ for rapeseed oil biodiesel, $0.00009 \mathrm{~g}$ for soybean oil biodiesel, $0.00014 \mathrm{~g}$ for coconut oil biodiesel and $0.00048 \mathrm{~g}$ for palm oil biodiesel. The variation of the mass of each piece of pipe after the test is shown in Figures 4 and 5.

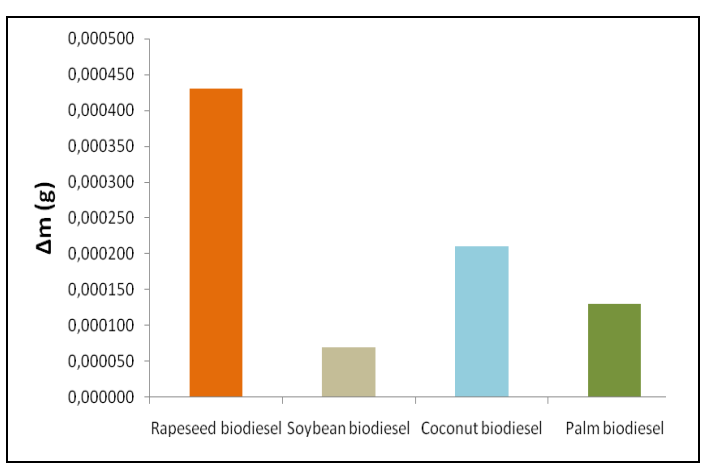

Fig. 4. Mass variation $(\Delta \mathrm{m})$ of pipe at $50^{\circ} \mathrm{C}$

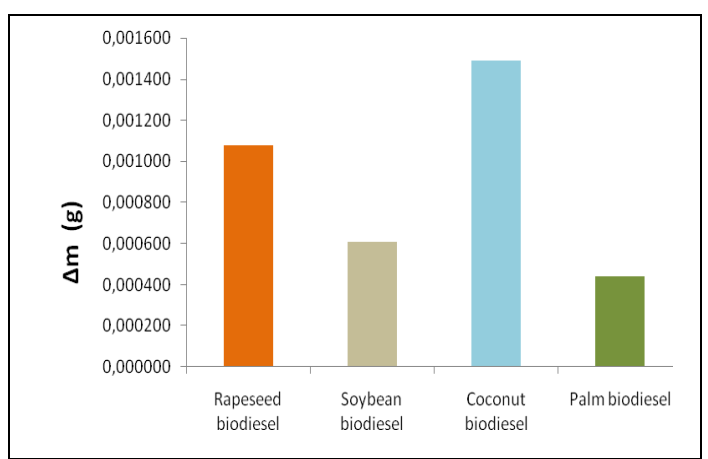

Fig. 5. Mass variation $(\Delta \mathrm{m})$ of pipe at $75^{\circ} \mathrm{C}$

\subsection{Acid value variation}

The variation of biodiesel acid value after the test is shown in Figures 6-9.

As can be seen, there is not a clear trend of the influence of the fatty acid composition in both mass loss and acid value increase. Influence of biodiesel from unsaturated 


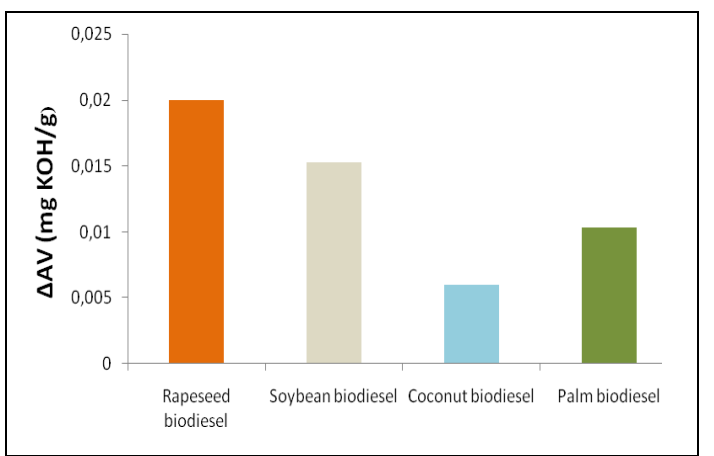

Fig. 6. Biodiesel acid value variation $(\Delta \mathrm{AV})$ when an injector sample is placed at $50^{\circ} \mathrm{C}$

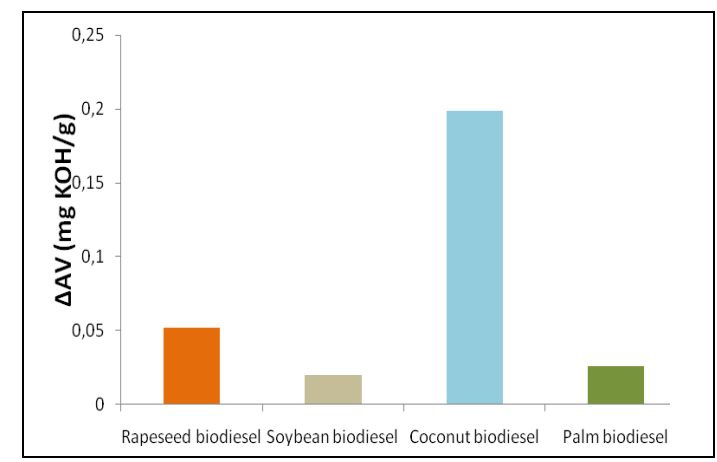

Fig. 7. Biodiesel acid value variation $(\Delta \mathrm{AV})$ when an injector sample is placed at $75^{\circ} \mathrm{C}$

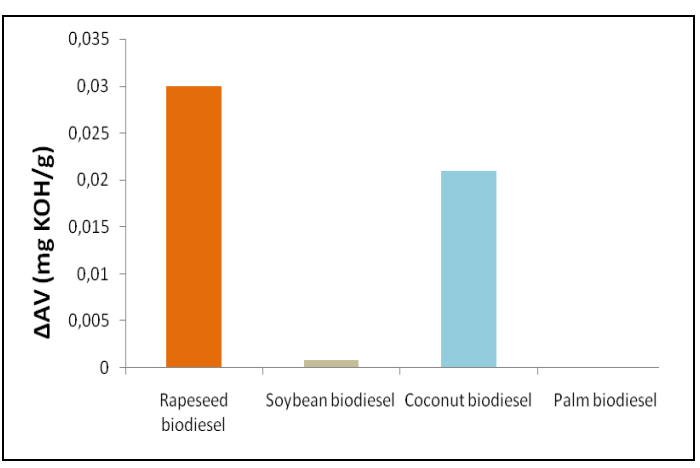

Fig. 8. Biodiesel acid value variation $(\Delta \mathrm{AV})$ when a pipe sample is placed at $50^{\circ} \mathrm{C}$

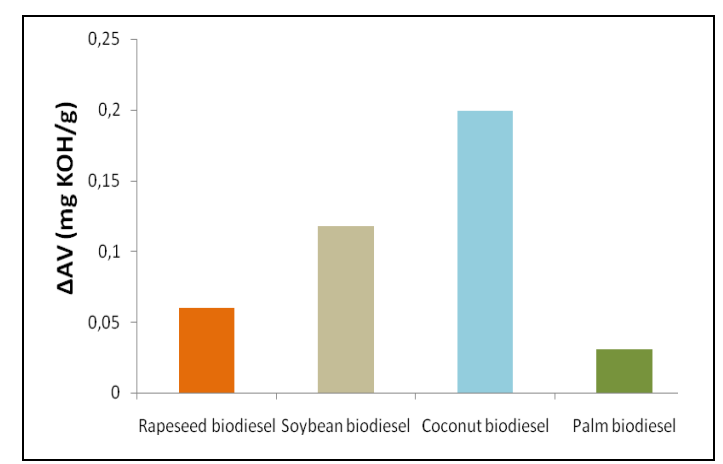

Fig. 9. Biodiesel acid value variation $(\Delta \mathrm{AV})$ when a pipe sample is placed at $75^{\circ} \mathrm{C}$ fatty acids (rapeseed and soybean oils) is indistinguishable from saturated ones (coconut and palm oils) either in terms of mass loss or acid value increase.

However, temperature significantly affects both biodiesel acidity and metal loss of mass. It has been shown that injector and pipe are made from different materials, thus influencing biodiesel in different ways. In this sense, palm oil biodiesel produces the greatest loss of mass of the injector, although it is the less degraded biodiesel. Rapeseed oil biodiesel produces the greatest loss of mass of the pipe, being also the most degraded biofuel at $50^{\circ} \mathrm{C}$; this position is conquered by coconut oil biodiesel, when temperature increases to $75^{\circ} \mathrm{C}$.

\section{Conclusion}

This paper investigated the corrosion behavior of metallic pieces of a diesel engine common rail injector system by static immersion, at different temperatures, in four types of biodiesel (from coconut oil, rapeseed oil, palm oil and soybean oil). After 15 days of immersion tests, it was found that there is a mass loss in both injector and pipe samples and an increase of biodiesel acid value. On the other hand, the increase of temperature, from $50^{\circ} \mathrm{C}$ to $75^{\circ} \mathrm{C}$, show a significant influence on both metal mass loss and biodiesel acid value increase.

\section{Acknowledgement}

This research supported by the Spanish Ministry of Economy and Competitiveness (ref. ENE2013-47769-R).

\section{References}

[1] M.P. Dorado, E. Ballesteros, J.A. de Almeida, C. Schellert, H.P. Löhrlein and R. Krause, "An alkali-catalyzed transesterification process for high free fatty acid waste oils", in Transactions of the ASAE (2002) Vol. 45 pp. 525-529.

[2] T. Tsuchiya, H. Shiotani, S. Goto, G. Sugiyama and A. Maeda, "Japanese standards for diesel fuel containing 5\% 
FAME blended diesel fuels and its impact on corrosion. SAE Technical Paper No. 2006-01-3303", (2006).

[3] G. Labeckas and S. Slavinskas, "Performance of directinjection off-road diesel engine on rapeseed oil", in Renewable Energy (2006) Vol. 31 pp. 849-863.

[4] M.A. Fazal, A. Hasseb and H.H. Masjuki, "Comparative corrosive characteristics of petroleum diesel and palm biodiesel for automotive materials", Elsevier, (2010).

[5] S.P. Singh and D. Singh, "Biodiesel production through the use of different sources and characterization of oils and their esters as the substitute of diesel: A review", in Renewable and Sustainable Energy Reviews (2010) Vol. 14 pp. 200-216.

[6] A. Alcántara Carmona, "Modelado y optimización del proceso de producción y uso de biodiesel ", doctoral thesis, Servicio de Publicaciones de la Universidad de Córdoba, (2014).

[7] S. Pinzi, J.M. Mata-Granados, F.J. Lopez-Gimenez, M.D. Luque de Castro and M.P. Dorado "Influence of vegetable oils fatty-acid composition on biodiesel optimization" in Bioresource Technology 102 (2011) 1059-1065. 